\title{
Vector Surveillance for Dengue, Chikungunya, Zika Virus and Yellow Fever at Three Blocks of Pakur Districts of Jharkhand, India
}

\author{
Ved Parkash', Sunita Patel $^{2}, \underline{\text { Sweta Bhan }}^{3}$, $\underline{\text { TG Thomas }}^{4}$ \\ ${ }_{1,2,3,4}$ Centre for Medical Entomology \& Vector Management, National Centre for Disease Control, 22-Sham Nath Marg, Delhi, India. \\ DOI: https://doi.org/10.24321/0019.5138.202044
}

\section{I $\quad \mathbf{N} \quad \mathbf{F} \quad \mathbf{O}$}

\author{
Corresponding Author: \\ Ved Parkash, Centre for Medical Entomology \& \\ Vector Management, National Centre for Disease \\ Control, 22-Sham Nath Marg, Delhi, India. \\ E-mail Id: \\ drvpmannncdc@gmail.com \\ Orcid Id: \\ https://orcid.org/0000-0002-0617-2773 \\ How to cite this article: \\ Parkash V, Patel S, Bhan S, Thomas TG. Vector \\ Surveillance for Dengue, Chikungunya, Zika Virus \\ and Yellow Fever at Three Blocks of Pakur Districts \\ of Jharkhand, India. J Commun Dis 2020; 52(4): \\ 77-80.
}

Date of Submission: 2020-05-16

Date of Acceptance: 2020-12-12

\section{$\begin{array}{llllllll}\mathbf{A} & \mathbf{B} & \mathbf{S} & \mathbf{T} & \mathbf{R} & \mathbf{A} & \mathbf{C} & \mathbf{T}\end{array}$}

\begin{abstract}
Vector borne diseases are a major public health problem in India. Dengue is endemic in almost all states and union territories. Aedes mosquitoes are known to transmit Dengue, Chikungunya, Zika virus and Yellow fever diseases to man in both rural and urban areas. Dengue has been restricted to urban area, but it has now spread to rural and tribal areas. An entomological survey was undertaken at selected villages of three Blocks of Pakur district i.e. Pakur, Maheshpur and Amarpada of Jharkhand to know the potential for the transmission of Dengue/Chikungunya, Zika virus and Yellow fever and thereby undertaking surveys of breeding places of the vector species in these area by assessing the vector indices i.e. House Index ( $\mathrm{HI})$, Breteau Index (BI) and Container Index ( $\mathrm{Cl}$ ) along with virus antigen detection. The entomological indices of $\mathrm{G}$ aneshpura, Datiapokhar and Longbahra villages of Maheshpur block recorded very high i.e. HI-28.5, 15.0 \& 10.0; $\mathrm{BI}-34.2,15.0$ \& 10.0 and $\mathrm{Cl}-11.8,8.8$ \& 4.8 respectively. The entomological indices of Pakur block, villages Jamsherpur, Malipada and Gopinathpur showed HI-7.3, 3.3 \& 2.3; BI-7.3, 3.3 \& 2.3 and Cl-3.5, $1.5 \& 1.3$ respectively. The entomological indices of Amarpada block, villages-Jagjitpur, Ambajora and Pakudh showed HI-6.6, 0.0 \& 0.0; BI6.6, 0.0 \& 0.0; and $\mathrm{Cl}-2.5,0.0 \& 0.00$ respectively. However, surveys revealed highest vector indices at Maheshpur block, followed by Pakur block and Amarpada block. Local health authorities of Maheshpur, Pakur and Amarpada blocks need to take cognizance of these facts with the presence of breeding potential areas and to develop micro action plan for appropriate vector control measures along with vector surveillance on regular basis.
\end{abstract}

Keywords: $\mathrm{HI}, \mathrm{Cl}, \mathrm{BI}$, Vector Surveillance

\section{Introduction}

Mosquitoes are known to transmit Yellow fever, Dengue, Chikungunya and Malaria diseases to human population in both rural and urban areas..$^{1-3}$ The mosquito borne infections are presently spreading from endemic to non-endemic area i.e. tribal area. Dengue vector control envisages reduction of aquatic stages of vector species through source reduction 
by eliminating breeding habits. The eradication of Aedes aegypti (L) from Brazil was achieved during the 1930s following a highly organized surveillance. ${ }^{4,5}$ Similarly, other larval control with more specific goals has resulted in reduction of dengue transmission in Australia, Indonesia, Thailand, and Brazil. ${ }^{6,7}$ In India, Aedes aegypti is known principal vector of dengue fever while dengue virus has also been recently detected in Aedes albopictus..$^{8-16}$ This communication presents the findings of some entomological surveys carried out in three blocks of Pakur district of Jharkhand state of India to assess the status of entomological indices with regard to the vectors of Yellow fever, Dengue, Chikungunya and Malaria and to assess potential risk of disease transmission.

\section{Materials and Methods}

\section{Entomological Surveillance}

A vector survey was conducted at three districts i.e. Pakur, Maheshpur and Amarpada of Jharkhand state of India for the vectors of Yellow fever, Dengue, Chikungunya and Malaria. The larvae collected from different types of containers were reared in 12 "X12" mosquito cages to confirm the species identity for the vector of Yellow fever, Dengue, Chikungunya and Malaria mosquitoes. From the field data pertaining to the breeding of vectors of Yellow fever, Dengue, Chikungunya and Malaria mosquitoes, various indices were calculated i.e. House Index (HI), Container Index $(\mathrm{Cl})$. The mean \pm SD for each index was calculated. House index represents the breeding prevalence of mosquitoes in surveyed houses in a locality. Container index represents prevalence of mosquitoes breeding in different types of water holding receptacles. For calculating proportion of positives containers, cumulative data for all the surveyed years of that particular place were taken into account.

\section{Detection of Dengue Virus (DENV) in Mosquitoes}

Larvae and adults were collected from the three districts i.e. Pakur, Maheshpur and Amarpada of Jharkhand state of India and brought to the Centre for Medical Entomology and Vector Management (National Centre for Disease Control, Delhi) for detection of DENV from mosquitoes by antigen-capture Enzyme Linked Immunosorbent Assay (ELISA) followed by standard protocol. Wild caught adult mosquitoes and adults reared from larvae were tested separately. Sex wise pool of 3-10 unfed Aedes aegypti mosquitoes were made and tested for presence of DENV using monoclonal antibody (MAb), D14G2 (1:1000) as capture antibody (broadly reactive against four serotypes of DENV) and MAb-peroxidase conjugate MAb 6B6C-1 as detector antibody (1:2000). The ELISA plate contained known DENV infected suckling mouse brain homogenate as positive control and the homogenate of uninfected adult Aedes aegypti as negative control. Mean \pm 4 Standard Deviation (SD) Optical Density (OD) of the normal laboratory reared mosquito pools (negative control) were taken as threshold level and any divergence of OD of the tested mosquito population that crosses this threshold level is considered as positive for DENV transmission.

\section{Result}

\section{Entomological Surveillance}

\section{Entomological Indices}

The Detailed of survey at selected villages of Pakur district of Jharkhand, India are given in the table.

The entomological indices of Ganeshpura, Datiapokhar and Longbahra villages of Maheshpur block recorded are $\mathrm{HI}-28.5,15.0$ \& 10.0; BI-34.2, 15.0 \& 10.0 and $\mathrm{Cl}-11.8,8.8$ \& 4.8 respectively. The entomological indices of Pakur block, villages Jamsherpur, Malipada and Gopinathpur shows HI-7.3, 3.3 \& 2.3; BI-7.3, 3.3 \& 2.3 and $\mathrm{Cl}-3.5,1.5$ \& 1.3 respectively. The entomological indices of Amarpada block, villages-Jagjitpur, Ambajora and Pakudh shows HI6.6, 0.0 \& $0.0 ; \mathrm{BI}-6.6,0.0 \& 0.0 ;$ and $\mathrm{Cl}-2.5,0.0 \& 0.00$ respectively (Table 1 ).

Table I.Locality wise Entomological indices of entomological surveillance

\begin{tabular}{|c|c|c|c|c|c|}
\hline Name of Block & Name of village & Name of PHC/ HSC & HI & CI & BI \\
\hline \multirow{4}{*}{ Maheshpur } & Ganeshpura & Barammasi & 28.5 & 11.5 & 34.2 \\
\cline { 2 - 6 } & Datiapokhar & Bhagaband & 15.0 & 8.8 & 15.0 \\
\cline { 2 - 6 } & Longbahra & Sonpatia & 10.0 & 4.8 & 10.0 \\
\hline \multirow{4}{*}{ Pakur } & Gopinathpur & Anjana & 2.3 & 1.3 & 2.3 \\
\cline { 2 - 6 } & Malipada & Sanajodi & 3.3 & 1.5 & 3.3 \\
\cline { 2 - 6 } & Jamsherpur & Beldenga & 7.3 & 3.5 & 0.0 \\
\hline \multirow{3}{*}{ Amarpada } & Ambajora & Amarpada & 0.0 & 2.5 & 6.0 \\
\cline { 2 - 6 } & Jagjitpur & Amarpada & 6.6 & 0.0 & 0.0 \\
\cline { 2 - 6 } & Pakudh & Chilgori & 0.0 & 2.0 \\
\hline
\end{tabular}

* House Index (HI), Container Index (Cl) and Breteau Index (BI). 


\section{Detection of Dengue Virus (DENV) in Mosquitoes}

A total of 14 pools of Aedes aegypti mosquitoes (male \& female) were tested for DENV infection from three districts i.e. Maheshpur, Pakur and Amarpada of Jharkhand state of India. However, all samples were found negative for DENV (Table 2).
2. World Health Organization. Prevention and Control of Yellow fever in Africa. WHO, Geneva, 1986.

3. Revision of International Health Regulations: Progress Report. Weekly Epidemiological Records 2002; 77 (19): 157-60.

4. World Health Organization. Dengue/Dengue haemor-

Table 2.Locality wise emergence of adult Aedes and other mosquitos' species

\begin{tabular}{|c|c|c|c|c|c|c|c|}
\hline \multirow{2}{*}{$\begin{array}{l}\text { Name of } \\
\text { block }\end{array}$} & \multirow{2}{*}{$\begin{array}{l}\text { Name of } \\
\text { village }\end{array}$} & \multicolumn{3}{|c|}{$\begin{array}{l}\text { Total emerged adult } \\
\text { mosquitoes }\end{array}$} & \multicolumn{3}{|c|}{$\begin{array}{l}\text { Identified adult Aedes and other mosquitoes } \\
\text { species }\end{array}$} \\
\hline & & Male & Female & $\begin{array}{l}\text { Total } \\
\text { pool }\end{array}$ & $\begin{array}{l}\text { Aedes } \\
\text { aegypti }\end{array}$ & $\begin{array}{c}\text { Aedes } \\
\text { albopictus }\end{array}$ & $\begin{array}{c}\text { Culex } \\
\text { quinquefasciatus }\end{array}$ \\
\hline \multirow{3}{*}{ Maheshpur } & Ganeshpura & 18 & 22 & 2 & 40 & 0 & 0 \\
\hline & Datiapokhar & 16 & 22 & 2 & 38 & 0 & 0 \\
\hline & Longbahra & 6 & 18 & 2 & 24 & 0 & 0 \\
\hline \multirow{3}{*}{ Pakur } & Gopinathpur & 7 & 4 & 2 & 11 & 0 & 0 \\
\hline & Malipada & 9 & 4 & 2 & 13 & 0 & 0 \\
\hline & Jamsherpur & 8 & 15 & 2 & 23 & 0 & 0 \\
\hline \multirow{3}{*}{ Amarpada } & Ambajora & 0 & 0 & 0 & 0 & 0 & 0 \\
\hline & Jagjitpur & 13 & 5 & 2 & 18 & 0 & 23 \\
\hline & Pakudh & 0 & 0 & 0 & 0 & 0 & 0 \\
\hline
\end{tabular}

\section{Conclusion}

The ecology of the three blocks is different from each other and shows different type of breeding potential i.e. Maheshpur-Earthen pots used for cattle feed, Earthen \& Cemented containers used for water storage; Pakhur - Big \& Kachha house, people stores the water in Earthen and metallic containers behind the residential area and keep their cattle behind their residence and Amarpada-people used to clean the floor by fresh cattle dung, cattle feeding in cemented tanks. The mother foci for the vector breeding remains in the cemented tanks and earthern pots and spreads overs to other metallic and plastic containers during the favourable conditions. As there is no regular mechanism of vector surveillance, community awareness and participation can play an important role in minimizing the breeding potential areas and thereby breeding places.

Local health authorities of Maheshpur, Pakur and Amarpada blocks need to take cognizance of these facts and develop a comprehensive micro action plan for appropriate vector control measures along with vector surveillance on regular basis.

\section{Conflict of Interest: None}

\section{References}

1. World Health Organization/ International Health Regulations, Third Annotated Edition. WHO/HQ, Geneva. 1983. rhagic fever prevention and control Programme in Thailand. WHO Project: ICP CTD 001, SEA/Haem. Fev./68, SEA/VBC/68. Geneva: World Health Organization, 1-47. 2. (a) World Health Organization Instructions for determining the susceptibility or resistance of adult mosquito to organochlorine, organophosphate and carbamate insecticides-Diagnostic test. WHO/ VBC/81.806. (b) World Health Organization. Instructions for determining the susceptibility or resistance of mosquito larvae to insecticides. WHO/VBC/81.807. 1999.

5. International Health Regulations adopted by the twenty-second World Health Assembly in 1969 and amended by the Twenty-sixth World Health Assembly in 1973 and the Twenty-fourth World Health Assembly in 1981, 3rd annotated ed. World Health Organization, Geneva, 1983.

6. Soper FL, Wilson DB, Lima S, et al. The organization of permanent nation-wide anti-aedes aegypti measures in Brazil. Am J Public Health Nations Health 1944; 34(7): 795.

7. Pontes RJS, Freeman J, Olivera-Limas JW et al. Vector densities that potentiate dengue outbreaks in a Brazilian city. Am J Trop Med Hyg 2000; 62: 378-83.

8. Sharma SN, Kumar S, Das BP et al. Entomological indices of Aedes aegypti at some international airports and seaports of southern India-A Report. J Commun Dis 2005; 37(3): 173-181. 
9. Kay BH, Barker-Hudson P, Hapgood GD et al. Aedes aegypti and dengue in the Townsville area, 1982-1985. Gen Appl Ent 1987; 19: 2-10.

10. Hart A. The DART-a new approach to dengue fever control. Wing Beats 2000; 10: 16-8.

11. Hoedojo, Suroso T. Aedes aegypti control through source reduction by community efforts in Pekalongan, Indonesia. Mosquito-Borne dis Bull 1990; 7: 59-62.

12. Bang $\mathrm{YH}$, Pant CP. A field trial of Abate larvicide for the control of Aedes aegypti in Bangkok, Thailand. Bull WHO 1972; 46: 416-25.

13. Kaul SM, Sharma RS, Sharma SN et al. Preventing dengue and DGHF. The role of entomological surveillance. J Com Dis 1998; 30: 187-92.

14. District guidelines for yellow fever surveillance. WHO, Geneva, 1998. Available from: https://apps.who. int/iris/bitstream/handle/10665/64384/www9834. 